\title{
HIDUP DALAM STIGMA: KEKERASAN DAN RELIGIUITAS BEJINGAN
}

\author{
Asmawati \\ Universitas Brawijaya Malang, Indonesia \\ Asmawati.suwarno@gmail.com \\ Sholih Muadi \\ Universitas Brawijaya Malang, Indonesia \\ Dr.Sholihmuadi@gmail.com \\ George Towar Ikbal Tawakkal \\ Universitas Brawijaya Malang, Indonesia \\ George.ikbal@ub.ac.id
}

\section{Living in Stigma: Violence And Religiousity of Bejingan}

\begin{abstract}
The purpose of this study is to find out that violence and religiosity can actually run side by side where both are able to make the figure of Bejingan have a different social strata from other communities. Violence is a characteristic of Bejingan in resolving conflicts in society while religiosity as a culture that has become ingrained in the community. To provide an understanding of the life of Bejingan in the community, this article explores how Bejingan lives in a standard of violence that has become a distinctive feature and cultural religiosity adopted in the community of Pamekasan Madura Regency. the method used in this study is qualitative with a case study approach where the researcher reveals in depth related to the life of Bejingan in Pamekasan Regency. The results obtained from this research are that Bejingan has long lived in stigma where its existence is always associated with violence and crime, whereas furthermore the role of Bejingan in the sphere of society has many benefits and benefits where security, conflict between citizens and the welfare of the community are influenced by the figure of Bejingan. Furthermore, the Bejong lives in a balanced balance of religiosity and violence where life is influenced by good relations between gods by practicing worship while still maintaining self-esteem in the distinctive characteristics of the heroism possessed. The scientific contribution of this article discusses the extension of the lives of local figures who have conflicting but side-by-side characteristics. Considering that the phenomenon that describes Bejingan is a conflict between culture and religion, then how can the conflict be balanced and go hand in hand. Then further research needs to be done.
\end{abstract}

Keywords: Violence; Religion; Bejingan

\section{Abstrak}

Tujuan yang ingin dicapai dari penelitian ini adalah untuk mengetahui kekerasan dan religiunitas sejatinya dapat berjalan berdampingan dimana keduanya mampu menjadikan sosok Bejingan memiliki strata sosial yang berbeda dari kalangan masyarakat lainya. Kekerasan menjadi ciri khas Bejingan dalam menyelesaikan konflik dalam masyarakat sedangkan religiunitas sebagai budaya yang telah mendarah daging dalam lingkungan masyarakat. Untuk memberikan pemahaman tentang kehidupan Bejingan dalam masyarakat artikel ini mengeksplorasi bagaimana Bejingan hidup dalam stigma kekerasan yang telah menjadi ciri khas yang dimiliki serta religiunitas budaya yang dianut dalam masyarakat Kabupaten Pamekasan Madura. metode yng digunkan dalam penelitian ini adalah kualitatif dengan pendekatn studi kasus dimana peneliti mengungkapkan secara 
mendalam terkait kehidupan Bejingan di Kabupaten Pamekasan. Hasil yang telah didapatkn dari penelitin ini adalah Bejingan telah lama hidup dalam stigma dimana keberadaanya selalu dikaitkan dengan kekerasan dan kriminalitas padahal lebih jauh peran Bejingan dalam lingkup masyarakat banyak memiliki manfaat dan kebaikan dimana kemanan, konflik antar warga serta kesejahterahan masyarakat dipengaruhi oleh sosok Bejingan. Lebih jauh lagi Bejingan hidup dalam keseimbangan religiunitas dan kekerasan yang seimbang dimana kehidupanya dipengaruhi oleh hubungan baik antar tuhan dengan menjalankan ibadah namun tetap mempertahankan harga diri dalam ciri khas jagoanisme yang dimiliki. Kontribusi keilmuan artikel ini mendiskusikan perluasan kehidupan tokoh lokal yang memiliki ciri khas yang bertentangan namun dapat berdampingan. Menimbang bahwa fenomena yang menggambarkan sosok Bejingan terdapat pertentangan antara budaya dan agama, maka bagaimana pertentangan tersebut dapat seimbang dan berjalan beriringan. Maka penelitian lebih lanjut perlu dilakukan.

Kata Kunci : Kekerasan; Religiunitas; Bejingan

\section{PENDAHULUAN}

Masyarakat Madura dikenal dengan citra simbolik kekerasan dan religiunitas yang telah menjadi stigma. Padahal kekerasan dan religiunitas memiliki makna yang bertentangan dimana kekerasan identik dengan kejahatan sedangkan religiunitas identik dengan sikap hidup asketik Meskipun pada dasarnya kekerasan dan religiunitas merupakan anak kandung dalam kehidupan suatu masyarakat. Hal tersebut dibuktikan pada keberadaan sososk Bejingan yang mampu hidup berdampingan dengan kekerasan dan religiunitas ${ }^{2}$. Bejingan sebagai tokoh lokal di Kabupaten Pamekasan yang memiliki julukan jagoanisme dan kekerasan menjadikan Bejingan berada pada citra negatif ${ }^{3}$. Jogoanisme yang melekat pada diri Bejingan tentu berlawanan dengan budaya masyarakat Madura dimana sangat memegang religiunitas dan ketaatan yang tinggi terhadap sang pencipta ${ }^{4}$. Tidak heran jika Bejingan hidup dalam bayangbayang stigma negatif dalam pandangan masyarakat luas. Meskipun sejatinya sedikit yang tahu bahwa Bejingan mampu menjalankan budaya religiunitas sekaligus ciri khas jagoanisme dalam kehidupan sehari-hari ${ }^{5}$.

\footnotetext{
1 Abdur Rozaki, "Social origin dan Politik Kuasa Blater di Madura," Kyoto Review of Southeast Asia 12 (2009).

2 Ishaq Abdussalam, "Reproduksi Kekuasaan Kyai Dan Blater Di Kabupaten Bangkalan,” DIMENSIJournal of Sociology 8, no. 1 (2015); Siti Nuruddiniyah, "Strategi politik Kyai dan Blater dalam pemilihan Kepala Desa di Desa Jangkar Kecamatan Tanah Merah Kabupaten Bangkalan” (PhD Thesis, IAIN Sunan Ampel Surabaya, 2010).

3 Rofiatus Solihah, "Kyai dan Blater Dalam Masyarakat Madura: Relasi Kekuatan Politik Lokal dalam Pilkades Desa Nagasareh Kecamatan Banyuates Sampang” (PhD Thesis, UIN Sunan Ampel Surabaya, 2015).

${ }^{4}$ Edi Susanto Edi Susanto, "Kepemimpinan [Kharismatik] Kyai Dalam Perspektif Masyarakat Madura," KARS A: Journal of Social and Islamic Culture 11, no. 1 (2012): 30-40.

${ }^{5}$ Usman Usman, "Blater, Pesantren Dan Pendidikan Formal," Islamuna: Jurnal Studi Islam 4, no. 2 (2017): 262-275; Ach Khoiri, "Kontrol Politik Kyai dan Blater dalam Pelaksanaan Pemilu; Kajian Kelemahan Ketentuan Hukum Pemilu Menghadapi Rezim Kembar Politik di Madura," VOICE JUSTISLA: Jurnal Hukum dan Keadilan 1, no. 2 (2017): 131-141.
} 
Sedikit dijelaskan bahwa Bejingan di Madura memiliki kedudukan sama dengan Blater dimana literasi banyak menyebutnya dengan istilah Blater. ${ }^{6}$ Segala ciri khas yang telah tercurahkan dalam diri Blater sama dengan Bejingan hanya saja yang membedakan adalah penyempatan nama. Sebutan Blater lebih dominan digunakan oleh masyarakat Madura bagian barat yaitu Sampang dan Bangkalan sedangkan Bejingan digunakan oleh masyarakat Madura bagian timur yaitu Sumenep dan Pamekasan. ${ }^{7}$ Meskipun ada literasi yang menjelaskan bahwa Blater dan Bejingan memiliki status sosial yang berbeda dimana Bejingan lebih rendah dari Blater dengan alasan Bejingan terkenal dengan sosok sombong, kasar dan membuat keonaran dan lain sebagainya ${ }^{8}$. Namun aktifitas diatas juga bisa melekat pada kaum Blater jadi sangat sulit membedakan keduanya. ${ }^{9}$

Literatur sebelumnya telah banyak mencurahkan perhatian terkait kehidupan Blater dimana diantaranya adalah penelitian Rozaky yang menjelaskan bagaimana kuasa Blater di Madura yang memecahkan aktor lokal kyai yang memiliki ciri khas religiunitas dengan Blater yang identik dengan ciri khas kekerasan dimana keberadaanya menjadi tokoh lokal sekaligus duduk di politik pemerintahan di Madura. ${ }^{10}$ Penelitian selanjutnya dilakukan oleh Ainillah yang menjelaskan terkait peran Blater dalam kontestasi politik desa dimana didalamnya menjelaskan bagaimana blater bertindak dalam proses politik desa dengan memafaatkan jagoanisme nya untuk menjadi elit lokal. ${ }^{11}$ Penelitian Kosim menjelaskan bagaimana Elite lokal kyai dan Blater dalam masyarakat Madura dimana menjelaskan peran kyai yang identik dengan nilai-nilai agama yang hanif serta Blater yang identik dengan kekerasan dimana didalamnya terdapat relasi yang berlangsung secara kompleks ${ }^{12}$. Dilanjutkan dengan penelitian Zamroni yang menjelaskan dinamika elite lokal Madura dimana berisi tentang sejarah yang menjelaskan bagimana kyai dan blater hidup sebagai elit lokal Madura. ${ }^{13}$ Dilengkapi penelitian Hannan yang menjelaskan terkait agama, kekerasan dan kontestasi politik elektoral dengan membahas

6 Abd Hannan dan Kudrat Abdillah, "HEGEMONI RELIGIO-KEKUASAAN DAN TRANSFORMASI SOSIAL Mobilisasi Jaringan Kekuasaan dan Keagamaan Kyai dalam Dinamika SosioKultural Masyarakat," Sosial Budaya 16, no. 1 (2019): 9-24.

${ }^{7}$ Mohammad Kosim Kosim, "Kyai dan blater (elite lokal dalam masyarakat Madura)," KARS A: Journal of Social and Islamic Culture 12, no. 2 (2012): 149-160.

8 Shohebul Umam, "Relasi Kuasa Dan Kesejahteraan Sosial," UIN Sunan Kalijaga, 2018.

9 Muhammad Adlin Sila, "Kiai dan Blater: Antara Kesalehan dan Kekerasan dalam Dinamika Politik Lokal di Madura,” Studia Islamika 26, no. 1 (10 April 2019), https://doi.org/10.15408/sdi.v26i1.11121.

${ }^{10}$ Rozaki, "Social origin dan Politik Kuasa Blater di Madura."

11 S. R. Ainilah, "Elite Politik Dalam Kontenstasi Di Desa Dengan Menggunakan Studi Peran Blater Dalam Pilkades Di Desa Banjar, Galis, Bangkalan Madura," Jurnal Politik Muda.[internet][diundub pada 2018 Desember4] 5, no. 3 (2016): 282-290.

12 Kosim, "Kyai dan blater (elite lokal dalam masyarakat Madura)."

${ }^{13}$ Imam Zamroni, "Dinamika Elit Lokal Madura," MASY AR AKAT: Jurnal Sosiologi, 2014, 23-48. 
terkait penggunaan simbol keagamaan kyai dan kekuasaan blater dalam pertarungan politik lokal di Madura. ${ }^{14}$

Secara empiris hasil penelitian kami menggambarkan literatur yang ada dalam beberapa cara. Pertama, sedikit melengkapi penelitian Rozaky dimana dalam penelitian kami menjelaskan kehidupan Bejingan dalam tatanan masyarakat dalam menjalankan dua peran penting yaitu religiunitas dan kekerasan. Kedua, sedikit berbeda dengan penelitian Ainillah yang membahas dalam lingkup politik disini kami menawarkan kehidupan sosial Bejingan. Ketiga, melengkapi penelitian Kosim dimana tidak membedakan antar kyai dan blater melainkan kehidupan Bejingan yang menyeimbangkan religiunitas dan kekerasan. Keempat, berbeda dengan penelitian Zamroni penelitian kami membahas implementasi nyata Bejingan sedangkan Zamroni membahas terkait sejarah elite lokal Madura ${ }^{15}$. Kelima melengkapi sedikit penelitian Hannan dimana penelitian kami terfokus pada Bejingan tidak terbagi pada fokus kyai.

Singkatnya, kerangka kerja yang diadopsi dalam artikel ini menangkap ide-ide dari literatur sebelumnya dengan menyatukan elemen-elemen baru. Artikel kami membuka jalan baru dimana kehidupan Bejingan dalam tatanan sosial masyarakat menarik untuk diperdalam. Ketika banyak literasi memberikan perhatian kepada hubungan kyai dan blater, maka artikel ini memberikan kebaruan mengingat Bejingan hidup dalam status sosial yang kaitanya dengan religiunitas namun memiliki sifat jagoanisme yang bertentangan dengan religiunitas.

Hasil kami konsisten dengan beberapa hal dimana Bejingan hidup dalam stigma jagoanisme yang identik dengan kekerasan yang ditunjukkan dengan pembuktian harga diri dalam menjaga status sosial yang tercipta dalam masyarakat. Bejingan hidup dalam lingkup dimana keseharianya berada pada sosok premanisme yang identik dengan berbuat kerusuhan. Kami harus mencatat bahwa artikel kami bukan pekerjaan pertama yang mengakui Bejingan sebagai tokoh lokal yang berpengaruh penting dalam tatanan masyarakat yang hidup dalam khas kekerasan dan kejahatan. Namun, lebih dari itu kami memberikan gambaran yang berbeda dimana religiunitas juga ikut andil dan berjalan beriringan dengan sikap Bejingan.

${ }^{14}$ Hannan dan Abdillah, "HEGEMONI RELIGIO-KEKUASAAN DAN TRANSFORMASI SOSIAL Mobilisasi Jaringan Kekuasaan dan Keagamaan Kyai dalam Dinamika Sosio-Kultural Masyarakat."

15 Imam Zamroni Imam Zamroni, "Kekuasaan Juragan dan Kiai di Madura," KARS A: Journal of Social and Islamic Culture 12, no. 2 (2012): 161-167. 


\section{METODE PENELITIAN}

Kabupaten Pamekasan menjadi satu tempat yang dipilih oleh peneliti dengan alasan bahwa minimnya literasi yang menjelaskan terkait Bejingan dalam proses pemilihan kepala desa. Meskipun tokoh Bejingan memiliki karakter yang sama dengan Blatter dimana telah banyak diteli oleh ilmuan sosial. Perbedaan memang hanya terletak pada sebutan nama mengingat bahwa di Madura memang setiap kabupatenya memiliki bahasa daerah masingmasing. Namun, untuk mengisi kekosongan literasi, peneliti memilih Kabupaten Pamekasan dengan ciri khas Bejingan sebagai makelar suara menjadi satu kajian yang menarik untuk dibahas.

Metode penulisan artikel ini menggunakan metode penelitian studi kasus untuk mengenali lebih dalam sosok Bejingan dalam tatanan kehidupan masyarakat ${ }^{16}$. Mengingat bahwa Bejingan merupakan tokoh lokal yang disegani dan sulit untuk melakukan komunikasi peneliti memanfaatkan akademisi yang memang bergelut dalam tulisan-tulisan terkait tokoh lokal Bejingan serta memanfaatkan wartawan yang mengenal Bejingan sebagai penyambung antara peneliti dan Bejingan. Peneliti mewawancarai total sembilan Bejingan yang menyebar di Kabupaten Pamekasan. Wawancara mendalam dilakukan selama kurang lebih satu bulan guna mendapatkan informasi yang lengkap. Peneliti juga melakukan wawancara informal kepada masyarakat bagaimana Bejingan bergelut langsung dalam proses penyelesaian konflik yang terjadi di masyarakat. Serta peneliti juga menanyakan terkait keseharian Bejingan dalam bersosialisasi dengan masyarakat ${ }^{17}$.

\section{PEMBAHASAN}

Orang Baik Dalam Stigma - Stasus Sosial Bejingan

Kehidupan Bejingan selalu disoroti oleh ilmuan-ilmuan sosial dimana keberadaanya berada pada lingkup kekerasan. Sering kali tergambar bahwa Bejingan sebagai tokoh lokal yang memiliki kekuatan hingga masyarakat dipaksa tunduk dan patuh akibat imbas dari ketidakberdayaan mereka melawan intimidasi. ${ }^{18}$ Diperkuat lagi dengan jagoanisme yang dimiliki bejingan memaksa bejingan menyelesaikan konflik dengan kekerasan atau dalam budaya masyarakat Madura disebut dengan Carok. Bejingan tidak segan melakukan carok ketika harga dirinya direndahkan. Ketika Bejingan tidak melakukan carok atau memilih untuk berdamai maka nama dan harga dirinya akan dipertaruhkan. Hal ini sesuai dengan adagium

${ }^{16}$ Robert K Yin, Case Study Research: Design and Methods, 2013.

17 John W. Creswell, Qualitative inquiry \&o research design: choosing among five approaches, 2nd ed (Thousand Oaks: Sage Publications, 2007).

18 Ali Sahab, "Politik Patron-Client di Kabupaten Sampang," Jurnal Adminstrasi Publik, 2012. 
masyarakat Madura yaitu `etembheng pote mata ango poteah tolang (daripada menahan malu lebih baik hilang nyawa saja). ${ }^{19}$ Dengan demikian tidak heran jika sosok Bejingan lebih dikenal dengan kekerasanya tidak hanya dikalangan masyarakat Madura melainkan di kalangan masyarakat luas. Apalagi literasi telah banyak mengungkap bagaimana carok dan kekerasan selalu menjadi sorotan yang menarik dikaji pada diri Bejingan.

Namun, hal mengejutkan peneliti temukan dengan mengungkap sosok Bejingan yang selama ini tak tersentuh dimana keberadaanya sangat dibutuhkan oleh masyarakat sekitar. Bejingan merupakan sosok orang kuat dalam suatu desa yang mampu memberikan perlindungan dan keselamatan secara fisik terhadap masyarakat. ${ }^{20} \mathrm{Hal}$ ini tergambar bagaimana Bejingan melindungi masyarakatnya dari segala konflik yang terjadi. Tidak hanya itu, keamanan juga menjadi tanggung jawab Bejingan untuk menjaga ternak dan barang masyarakatnya. Tidak heran jika keberadaan Bejingan mampu membuat kampung mereka aman dengan alasan orang yang akan masuk untuk bertindak kriminal akan berfikir berulang kali menimbang keberadaan Bejingan yang tak segan menyelesaikan masalah dengan carok yang imbasnya pada pertaruhan nyawa. Dengan demikian keberadaan Bejingan mampu sebagai penentu aman atau tidaknya suatu desa dari aksi pencurian, perampokan dan pertikaian antar warga.

Tidak terbatas pada persoalan keamanan saja. Bejingan dikenal dalam kalangan masyarakat sebagai sosok yang memiliki perekonomian yang tinggi dibandingkan masyarakat lainya. Tak heran jika Bejingan sering berbagi kepada masyarakat yang tidak mampu atau yang membutuhkan. Hal ini bertujuan menjaga eksistensi Bejingan dalam kalangan masyarakat dimana rasa ingin dihormati dan disegani membawa kewibawaan pada sosok Bejingan. Kemapanan ekonomi yang dimiliki Bejingan juga mampu mengantarkan Bejingan duduk pada kursi pemerintahan formal dimana kedudukanya sebagai kepala desa yang mampu memimpin desa dan memberikan kesejahterahan. Namun, stigma negatif dalam hal ini tidak dapat dihindarkan mengingat banyak literasi yang membahas terkait kekerasan yang terjadi dalam Pemilihan Klebun (kepala desa) yang melibatkan tokoh utama Bejingan dalam peranya sebagai makelar suara. Permasalahan terletak pada bagaimana Bejingan dengan mempertaruhkan harga dirinya dalam prospek kemenangan pemilihan klebun. Dengan begitu Bejingan melakukan segala macam cara untuk mempertahankan martabatnya meskipun jalan yang harus ditempuh

19 Ach Khatib, "Kontestasi Langgar dan Pesantren (Studi Atas Pranata Keagamaan Lokal di Sumenep Madura)," 'Anil Islam: Jurnal Kebudayaan dan Ilmu Keislaman 9, no. 1 (2016): 32-54.

${ }^{20}$ Rozaki Abdur, Menabur Kharisma Menuai Kuasa: Kiprah Kyai dan Blater Sebagai Rezim Kembar di Madura (Yogjakarta: Pustaka Marwa, 2004), 9. 
adalah carok. Tidak jarang pula Bejingan secara terang-terangan mencari dukungan pemilih dengan mengancam jika tidak mau memilih kandidatnya maka wilayahnya akan tidak aman. Dari sinilah Bejingan dinilai masyarakat mampu melakukan segala cara untuk mempertahankan harga dirinya meski nyawa sebagai taruhanya. Diperkuat dengan pendapat yang menyatakan bahwa dalam kemenangan cos politik mereka, Bejingan tidak segan menggunakan cara kasar dengan berupaya menggiring masyarakat untuk memilih kandidatnya. $^{21}$

\section{Gambar 1}

\section{Penyelesaian Konflik Dengan Carok}

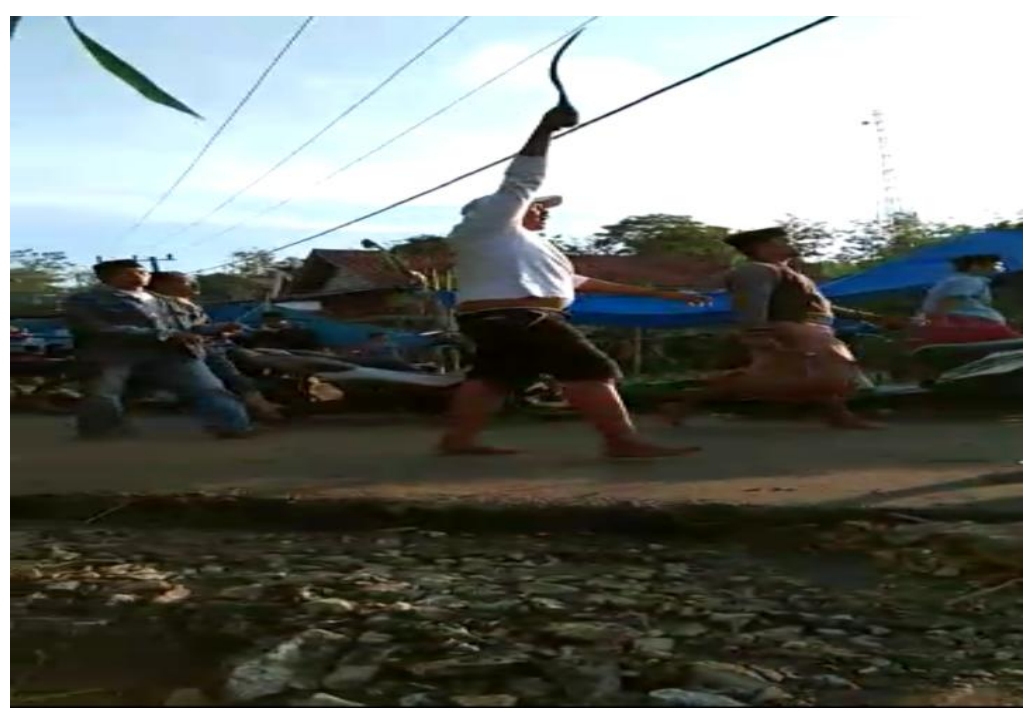

Sumber : Data Peneliti

Dari berbagai sudut pandang dapat dikatakan Bejingan dalam segala kekerasanya sejatinya demi mempertahankan martabat dan harga dirinya dimata masyarakat. Dengan demikin Bejingan tetap berada para status sosial yang disegani masyarakat. Tidak dapat dipungkiri segala yang dilakukan Bejingan dalam mempertahankan harga dirinya memiliki maksut yang baik dalam menjalankan peran nya di lingkup tatanan masyarakat. sedikit peneliti kutip dari Juwari sebagai tokoh Bejingan yang mengatakan bahwa “iyeh, lakar sengkok terkenal dengan kekerasan sabeb adi en sengkok tak lopot dheri kakerrasen, tapeh kabbhi kaanggubuy kabeghusennah masyarakat kiah. Mon engkok esegani ekatoko'en pasteh tak kerah bedeh oreng se bengal masok ka disanah sengkok kaangghuy alakonih kejahadhen akantah perampokan ben maleng. Ajieh pastenah ngontongaghi kaangghuy masyarakat e disah kauleh sadhejeh" ${ }^{\text {22 }}$ yang secara kasar dapat

${ }^{21}$ Abdussalam, "Reproduksi Kekuasaan Kyai Dan Blater Di Kabupaten Bangkalan."

22 Wawancara dengan Bejingan pada 2 Maret 2020 
diartikan "ya memang saya dikenal dengan kekerasan karna hidup saya tidak lepas dari kekerasan tapi semuanya untuk kebaikan masyarakat juga. Kalau saya disegani pasti tidak ada orang yang berani masuk desa kami untuk melakukan kejahatan misalnya perampokan dan pencurian. Itu juga pasti akan menguntungkan untuk masyarakat di desa kami."

\section{Agama dan Kekerasan}

Agama dikatakan sebagai kepercayaan atau keyakinan seseorang yang mampu memberikan bimbingan ketika seseorang melakukan segala macam tindakan. ${ }^{23}$ Dalam bentuk keyakinan, Agama dipercayai sebagai sumber ajaran moral bagi seseorang. ${ }^{24}$ Dengan demikian dapat dikatakan bahwa agama mampu mengajarkan penganutnya untuk berperilaku mulia. Dihadapkan pada situasi ini Bejingan hidup dalam dua simbolik yang bertentangan ${ }^{25}$. Masyarakat pamekasan yang menjuluki kotanya dengan gerbang salam menunjukkan seberapa religiusnya masyarakat dibentuk untuk memiliki moral dan akhlak yang baik. Terlebih lagi bentuk ketaatan dan kepatuhan Masyrakat madura dalam agama dibuktikan pada ungkapan budaya : Buppa`, Babbu, Guru, Rato (ayah, ibu, guru dan pemimpin formal) . keempat figur tersebut mencerminkan tingkat kepatuhan orang Madura dalam kehidupan. ${ }^{26}$ Selain tingkat kepatuhan, tingginya semangat keagamaan masyarakat dibuktikan juga dengan jumlah masjid, pesantren dan institusi islam serta setiap rumah warga pasti terdapat langgar dan lain sebagainya. ${ }^{27}$ Bertentangan dengan ciri khas Bejingan yang identik dengan kekerasan dan carok seakan jauh dari kata moral yang baik. Ditambah lagi literasi banyak membahas terkait citra negatif yang dimiliki Bejingan ${ }^{28}$. Dengan demikian Bejingan hidup dalam stigma negatif jauh dari religiunitas budaya yang dianut masyarakat Madura khusunya Pamekasan.

Budaya carok yang menjadi ciri khas Bejingan dalam penyelesaian suatu konflik tentu sangat berlawanan dengan ajaran agama yang menggambarkan perdamaian, kebahagiaan dan hegemoni. Dengan demikian kehidupan Bejingan masih belum optimal dalam menjalankan religiunitas dan budaya secara bersamaan. Namun, tidak dapat dikatakan gagal menjalankanya dengan melihat fenomena-fenomena mengejutkan dimana peneliti menemukan bahwa

${ }^{23}$ Ahmad Muttaqin, "Agama dalam representasi ideologi media massa," KOMUNIKA: Jurnal Dakwah dan Komunikasi 6, no. 2 (2012).

${ }^{24}$ Zuhairansyah Arifin, "Pendidikan Moral Dalam Multi Perspektif," Sosial Budaya 8, no. 1 (2011): 132_ 151.

25 Samsul Arifin dan Akhmad Zaini, "Dakwah Inklusif di Kalangan Bajingan: Membedah Komitmen Bekas Bajingan dalam Membangun Peradaban, Perspektif Psikologi Sosial," Jurnal Dakwab 19, no. 1 (2018): 31 52.

${ }^{26}$ A Latief, Madura yang Patub? Kajian Antropologi Mengenai Budaya Madura (Jakarta: Ceric Fisip UI, 2003), 1.

27 Zainuddin Syarif, "Rekulturasi Pendidikan Islam di Tengah Budaya Carok di Madura," KARS A: Journal of Social and Islamic Culture 22, no. 1 (2015): 114-136.

28 A. Latief Wiyata, Carok; Konflik Kekerasan \& Harga Diri Orang Madura (Lkis Pelangi Aksara, 2002). 
Bejingan hidup dalam ketaatan dalam urusan beribadah kepada tuhan ${ }^{29}$. Hal ini ditunjukkan dengan tidak meninggalkan kewajibanya dalam menjalankan ibadah wajib yang dianjurkan oleh agama. tidak heran jika ditemui Bejingan-Bejingan ketika azan akan berangkat ke masjid dengan menggunakan sarung hanya untuk beribadah. Lebih dari itu, generasi mereka juga diajarkan untuk menuntut ilmu agama di pesantren agar tidak buta dalam urusan agama. sesuai dengan ungkapan Supardi selaku Bejingan yang menyatakan bahwa "maskeh engkok lakoh kasar, acarok, arampok, tape engkok pagun ibede ka pangeran sapah taoh pangeran gik mempertimbangkan ibedenah engkok",30 yang secara kasar dapat diartikan "meskipun saya sering melakukan carok, tapi saya tidak boleh lupa untuk beribadah karena tuhan akan memperhitungkan sholat saya"

\section{KESIMPULAN}

Kehidupan Bejingan yang terbenturkan atas kebudayaan religiunitas yang dianut oleh masyarakat Madura khususnya Kabupaten Pamekasan memberikan dampak besar dari status sosial yang melekat pada diri Bejingan yaitu harga diri dan jagoanisme. Kenyataanya, Bejingan mampu hidup berdampingan dengan masyarakat dimana Bejingan tetap melakukan kegiatan keagamaan serta melakukan ibadah yang telah diwajibkan dalam agama. lebih dari itu Bejingan mampu hidup berdampingan dengan masyarakat dan menjalankan peranya sesuai dengan kebutuhan masyarakat dimana Bejingan yang identik dengan kekerasan mampu menjadi klebun atau kepala desa yang mampu menjadikan desanya aman dari segala bentuk pencurian dan perampokan. Meskipun dalam kenyataanya Bejingan belum mampu menjalankan kebudayaan religiunitas dan stigma yang melekat pada dirinya secara berdampinan namun Bejingan mampu menjadi tempat dimana masyarakat mampu melimpahkan harapanya dengan mengandalkan sosok jagoanisme untuk keuntungan masyarakat di kalangan desanya.

\section{REFERENSI}

A Latief. Madura yang Patub? Kajian Antropologi Mengenai Budaya Madura. Jakarta: Ceric Fisip UI, 2003.

Abdur, Rozaki. Menabur Kharisma Menuai Kuasa: Kiprah Kyai dan Blater Sebagai Rez̧im Kembar di Madura. Yogjakarta: Pustaka Marwa, 2004.

Abdussalam, Ishaq. "Reproduksi Kekuasaan Kyai Dan Blater Di Kabupaten Bangkalan." DIMENSI-Journal of Sociology 8, no. 1 (2015).

29 YANWAR PRIBADI, "Jawara Banten dan Blater Madura: Studi Komparasi Hubungan SosialKeagamaan Mereka dengan Kiai," Tarkiya 16, no. 02 (2017): 245-281.

${ }^{30} \mathrm{~W}$ wancara dengan Bejingan pada Tanggal 10 Maret 2020 
Ainilah, S. R. "Elite Politik Dalam Kontenstasi Di Desa Dengan Menggunakan Studi Peran Blater Dalam Pilkades Di Desa Banjar, Galis, Bangkalan Madura.” Jurnal Politik Muda. [internet][diunduh pada 2018 Desember4] 5, no. 3 (2016): 282-290.

Arifin, Samsul, dan Akhmad Zaini. "Dakwah Inklusif di Kalangan Bajingan: Membedah Komitmen Bekas Bajingan dalam Membangun Peradaban, Perspektif Psikologi Sosial." Jurnal Dakwah 19, no. 1 (2018): 31-52.

Arifin, Zuhairansyah. "Pendidikan Moral Dalam Multi Perspektif." Sosial Budaya 8, no. 1 (2011): 132-151.

Creswell, John W. Qualitative inquiry \& research design: choosing among five approaches. 2nd ed. Thousand Oaks: Sage Publications, 2007.

Hannan, Abd, dan Kudrat Abdillah. "HEGEMONI RELIGIO-KEKUASAAN DAN TRANSFORMASI SOSIAL Mobilisasi Jaringan Kekuasaan dan Keagamaan Kyai dalam Dinamika Sosio-Kultural Masyarakat.” Sosial Budaya 16, no. 1 (2019): 9-24.

Khatib, Ach. "Kontestasi Langgar dan Pesantren (Studi Atas Pranata Keagamaan Lokal di Sumenep Madura)." 'Anil Islam: Jurnal Kebudayaan dan Ilmu Keislaman 9, no. 1 (2016): 32-54.

Khoiri, Ach. "Kontrol Politik Kyai dan Blater dalam Pelaksanaan Pemilu; Kajian Kelemahan Ketentuan Hukum Pemilu Menghadapi Rezim Kembar Politik di Madura." VOICE JUSTISLA: Jurnal Hukum dan Keadilan 1, no. 2 (2017): 131-141.

Kosim, Mohammad Kosim. "Kyai dan blater (elite lokal dalam masyarakat Madura)." KARS A: Journal of Social and Islamic Culture 12, no. 2 (2012): 149-160.

Muttaqin, Ahmad. "Agama dalam representasi ideologi media massa." KOMUNIKA: Jurnal Dakwah dan Komunikasi 6, no. 2 (2012).

Nuruddiniyah, Siti. "Strategi politik Kyai dan Blater dalam pemilihan Kepala Desa di Desa Jangkar Kecamatan Tanah Merah Kabupaten Bangkalan.” PhD Thesis, IAIN Sunan Ampel Surabaya, 2010.

PRIBADI, YANWAR. "Jawara Banten dan Blater Madura: Studi Komparasi Hubungan Sosial-Keagamaan Mereka dengan Kiai.” Tazkiya 16, no. 02 (2017): 245-281.

Rozaki, Abdur. "Social origin dan Politik Kuasa Blater di Madura." Kyoto Review of Southeast Asia 12 (2009).

Sahab, Ali. "Politik Patron-Client di Kabupaten Sampang." Jurnal Adminstrasi Publik, 2012. 
Sila, Muhammad Adlin. "Kiai dan Blater: Antara Kesalehan dan Kekerasan dalam Dinamika Politik Lokal di Madura." Studia Islamika 26, no. 1 (10 April 2019). https://doi.org/10.15408/sdi.v26i1.11121.

Solihah, Rofiatus. "Kyai dan Blater Dalam Masyarakat Madura: Relasi Kekuatan Politik Lokal dalam Pilkades Desa Nagasareh Kecamatan Banyuates Sampang.” PhD Thesis, UIN Sunan Ampel Surabaya, 2015.

Susanto, Edi Susanto Edi. "Kepemimpinan [Kharismatik] Kyai Dalam Perspektif Masyarakat Madura." KARS A: Journal of Social and Islamic Culture 11, no. 1 (2012): 30-40.

Syarif, Zainuddin. "Rekulturasi Pendidikan Islam di Tengah Budaya Carok di Madura." KARS A: Journal of Social and Islamic Culture 22, no. 1 (2015): 114-136.

Umam, Shohebul. "Relasi Kuasa Dan Kesejahteraan Sosial.” UIN Sunan Kalijaga, 2018.

Usman, Usman. "Blater, Pesantren Dan Pendidikan Formal.” Islamuna: Jurnal Studi Islam 4, no. 2 (2017): 262-275.

Wiyata, A. Latief. Carok; Konflik Kekerasan \& Harga Diri Orang Madura. Lkis Pelangi Aksara, 2002.

Yin, Robert K. Case Study Research: Design and Methods, 2013.

Zamroni, Imam. "Dinamika Elit Lokal Madura.” MASYARAKAT: Jurnal Sosiologi, 2014, 2348.

Zamroni, Imam Zamroni Imam. "Kekuasaan Juragan dan Kiai di Madura." KARS A: Journal of Social and Islamic Culture 12, no. 2 (2012): 161-167. 